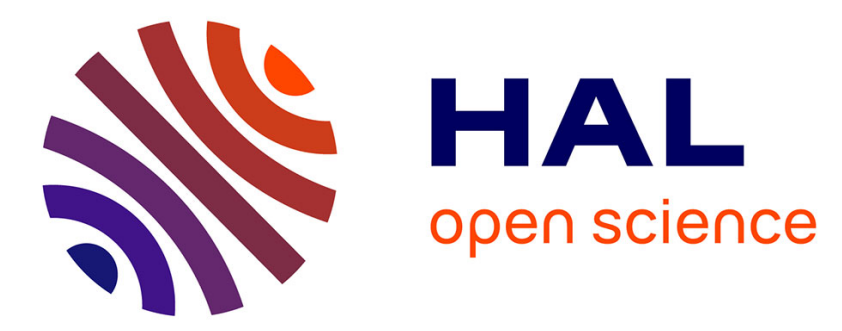

\title{
Relation between cognitive restraint and weight: Does a content validity problem lead to a wrong axis of care?
}

\author{
Sabrina Julien Sweerts, Damien Fouques, Baptiste Lignier, Gérard
}

Apfeldorfer, Katherine Kureta-Vanoli, Lucia Romo

\section{- To cite this version:}

Sabrina Julien Sweerts, Damien Fouques, Baptiste Lignier, Gérard Apfeldorfer, Katherine KuretaVanoli, et al.. Relation between cognitive restraint and weight: Does a content validity problem lead to a wrong axis of care?. Clinical obesity, 2019, 9 (5), 10.1111/cob.12330 . hal-02365995

\section{HAL Id: hal-02365995 \\ https://hal.parisnanterre.fr/hal-02365995}

Submitted on 15 Nov 2019

HAL is a multi-disciplinary open access archive for the deposit and dissemination of scientific research documents, whether they are published or not. The documents may come from teaching and research institutions in France or abroad, or from public or private research centers.
L'archive ouverte pluridisciplinaire HAL, est destinée au dépôt et à la diffusion de documents scientifiques de niveau recherche, publiés ou non, émanant des établissements d'enseignement et de recherche français ou étrangers, des laboratoires publics ou privés. 


\title{
Relation between cognitive restraint and weight: Does a content validity problem lead to a wrong axis of care?
}

\author{
Sabrina Julien Sweerts ${ }^{1}$ | Damien Fouques ${ }^{1}$ | Baptiste Lignier ${ }^{2,3}$ | \\ Gérard Apfeldorfer $^{4}$ | Katherine Kureta-Vanoli ${ }^{4}$ | Lucia Romo ${ }^{1,5}$
}

${ }^{1}$ EA4430 CLIPSYD, UFR SPSE, Paris Nanterre University, Nanterre, France

${ }^{2}$ Department of Psychology, Laboratoire Psy-DREPI, EA 7458, University of Bourgogne Franche-Comté, Dijon, France

${ }^{3}$ Psychotherapy Area, pôle B Côte-d'Or South of General Psychiatry, La Chartreuse, Dijon,

France

${ }^{4}$ Groupe de Réflexion sur l'obésité et le surpoids (G.R.O.S.), Think Tank on Obesity and Overweight, Paris, France

${ }^{5} \mathrm{CMME}$, Sainte-Anne's Hospital, Unité Inserm U 894 CPN, Paris, France

\section{Correspondence}

Sabrina Julien Sweerts, EA4430 CLIPSYD, UFR SPSE, Paris Nanterre University, Nanterre, France.

Email: sabrinajuliensweerts@gmail.com

\begin{abstract}
Summary
The aim of this research is to examine the relation between weight and cognitive restraint (CR), which is the intention to control food intake in order to maintain or lose weight, in a general French population sample. Is CR more prevalent in individuals with obesity than overweight, underweight or normal-weight subjects in this cross-sectional study? Are people affected by obesity non-restrained eaters? A total of 507 French people ( $80.2 \%$ women and $19.8 \%$ men), aged $18-78$ years, responded to an online questionnaire. It appears that the most used questionnaire measuring CR has content validity problems as it seems to measure effective control and not the intention. Therefore, a numeric scale was used to answer the questions. Even if it is not possible in this study to test a causal link with latent variable modelling, our results seem to show that people with obesity more frequently intend to eat less or to eat healthier and/or to eat less sugar and fat than other people in order to control their weight. However, people affected by obesity do not succeed in so doing. These results raise the question of treatments advocating the increase of self-control. Finally, it would be necessary to obtain a real, scientific consensus on what CR is and on how to measure it in order to study the most effective treatments for people with overweight or obesity.
\end{abstract}

\section{KEYWORDS}

cognitive restraint, intuitive eating, obesity, overweight, self-control

\section{1 | INTRODUCTION}

Cognitive restraint $(\mathrm{CR})$ is the intention to control food intake in order to maintain or lose weight. ${ }^{1-3}$ The impact of CR on weight is controversial. Many studies have shown a correlation between weight or body mass index (BMI) and CR, either negative ${ }^{4,5}$ or positive. ${ }^{6}$

The theory of CR divides people into the "restrained eaters group" or "non-restrained eaters group." It explains that restrained eaters develop an alteration in the internal perception of hunger and satiety,

Abbreviations: BFI, Big Five Inventory; BMI, body mass index; CR, cognitive restraint; PCL, Post-Traumatic Stress Disorder Checklist; TFEQ-21, The Three Factor Eating Questionnaire. disinhibition, emotional dysregulation and a decrease of self-esteem and body satisfaction. ${ }^{3,7-9}$ However, many studies have shown the opposite and have therefore promoted the increase of CR to treat overweight and obesity. ${ }^{10}$

The question still remains: should we reduce or increase $C R$ in people affected with overweight or obesity? Before trying to answer this question, we should ask another: how can we measure CR?

The Three Factor Eating Questionnaire (TFEQ-21), ${ }^{11}$ is the most used questionnaire to assess $\mathrm{CR}^{4-6}$ However, this tool could have content validity problems. Indeed, the reading of the items indicates that it measures "effective control" rather than "the intention to control", as shown is Table 1. 
TAB LE 1 Item of the cognitive restraint scale of the TFEQ-21

\begin{tabular}{|c|c|}
\hline $\begin{array}{l}\text { Item } \\
\text { number }\end{array}$ & Item of the cognitive restraint scale of the TFEQ-21 \\
\hline 5 & $\begin{array}{l}\text { I don't eat some kinds of foods because they can make } \\
\text { me fat }\end{array}$ \\
\hline 11 & $\begin{array}{l}\text { I eat less than I want at meal times to stop myself from } \\
\text { putting on weight }\end{array}$ \\
\hline 17 & $\begin{array}{l}\text { How often do you avoid eating or buying tempting } \\
\text { foods? }\end{array}$ \\
\hline 18 & $\begin{array}{l}\text { How often would you eat less than you wanted to in a } \\
\text { meal? }\end{array}$ \\
\hline 21 & $\begin{array}{l}\text { What types of eater are you on a scale of } 1 \text { to } 8 \text { ? Where } \\
1 \text { means "I eat whatever I want, whenever I want" and } \\
\text { where } 8 \text { means "I am careful about what I eat to } \\
\text { control my weight" }\end{array}$ \\
\hline
\end{tabular}

Abbreviation: TFEQ-21, The Three Factor Eating Questionnaire.

The TFEQ-21 could better identify individuals who are currently dieting ${ }^{12}$ and succeeding. CR is the intention to control food intake, ${ }^{13}$ not the most effective control. This content validity problemprobably due to an unfortunate broadening of its definition-could explain divergent conclusions in the studies. In fact, the two opposite clinical implications-dieting vs no dieting-continue.

The aim of this research is to examine the relation between $\mathrm{BMI}$ and $C R$ in a sample of the general French population. First, we will focus on the following questions: is CR more prevalent in individuals with obesity than overweight, underweight or normal-weight subjects? Are people affected by obesity non-restrained eaters?

Moreover, other factors could contribute to explaining BMI, such as personality, ${ }^{14,15}$ physical activity ${ }^{16}$ and traumatic events. ${ }^{17}$ So, the question is: does the CR determine the BMI, and if so, how much does it weigh when the other known factors are controlled?

\section{2 | METHODS}

\section{$2.1 \mid$ Procedures}

A questionnaire was created and administrated via the Qualtrics $\complement$ secure platform to guarantee security and anonymity. The link to the study was sent via email or via social media (Facebook, Linkedln). It took 10 minutes to complete the questionnaires. The study followed the ethical guidelines of the Declaration of Helsinki. ${ }^{18}$

\section{2 | Participants}

A total of 507 French people (80.2\% women and $19.8 \%$ men), aged 18-78 years $(M=37.8, S D=13.6)$, responded to the internet Qualtrics $^{(}$questionnaire; 6.1\% were underweight $(\mathrm{BMI}<18.5$; $\mathrm{N}=31), 54.2 \%$ had normal weight $(18.5<\mathrm{BMI}<25 ; \mathrm{N}=275)$, $24.5 \%$ were overweight $(25 \leq \mathrm{BMI}<30 ; \mathrm{N}=124)$, and $15.2 \%$ were obese $(\mathrm{BMI} \geq 30 ; \mathrm{N}=77)$.

\section{$2.3 \mid$ Measures}

CR was measured using a numeric rating scale (NRS) from 0 to 10 . Participants had to answer the question: "How much do you intend to control your diet in order to control your weight?," With 0 corresponding to "not at all, never" and 10 to "tremendously and constantly." Weight and height were filled out by the participants. BMI was calculated.

Personality was measured using the short form of the Big Five Inventory $^{19}$ (BFI). This 10-item self-reported measure describes five personality dimensions: E (Extraversion), A (Agreeableness), C (Conscientiousness), N (Neuroticism) and O (Openness).

Physical activity was measured by the Godin Leisure Time Exercise Questionnaire. ${ }^{20}$ This questionnaire measures the actual weekly physical activity by noting the number of physical activities of at least 30 minutes depending on the intensity (high, moderate or low).

Finally, the Post-Traumatic Stress Disorder Checklist (PCL) events, ${ }^{21}$ a 17 -item self-reported scale, was used to measure the intensity of psychotraumatic symptoms. ${ }^{22}$ After the subject has claimed to have had a stressful life event and has indicated the date of the most recent event and briefly explained what the event was, he or she is asked to complete, on a 5-point Likert scale, the intensity of the event, with 1 corresponding to "not at all" and 5 to "very often."

\subsection{Data analyses}

Jamovi was used for statistical analyses. A one-way analysis of variance (ANOVA) was conducted to test the impact of the CR on the BMI. The sample was split into four BMI groups in accordance with the World Health Organization classification (group 1, BMI < 18.5; group 2, $18.5 \leq \mathrm{BMI}<25$; group 3, $25 \leq \mathrm{BMI}<30$; group 4, $\mathrm{BMl} \geq 30$ ). Correlations were calculated between $C R$ and weight, between $C R$ and $\mathrm{BMI}$ and between weight and all other variables. Finally, all the variables were included in a linear regression model predicting weight.

\section{3 | RESULTS}

\section{1 | ANOVA}

Results showed an association between CR and BMI (F[3379] = 9049, $P<.001$ ) (Figure 1).

\subsection{Correlation between $\mathrm{CR}$ and weight}

CR and weight were positively correlated $(r=.13, P=.008$,), as well as $\mathrm{BMI}$ and $\mathrm{CR}(r=.184, P<.001)$.

\section{3 | Others significant correlations with weight}

BFI N $(r=-.098, P<.035)$ and BFI C $(r=-.12, P=.010)$ were negatively correlated with weight, as was PCL-S $(r=-.148, P=.003)$. 


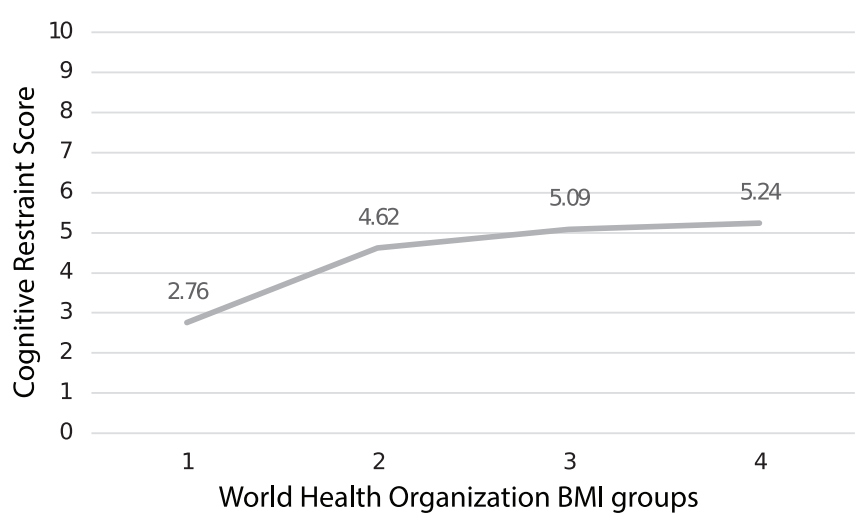

FIGURE 1 Mean cognitive restraint (CR) based on body mass index (IMCCAT). World Health Organization body mass index (BMI) groups: 1 = underweighted group (BMI < 18.5); 2 = (18.5 $\leq \mathrm{BMI}<25)$; 3 = individuals with overweight $(25 \leq \mathrm{BMI}<30) ; 4=$ individuals with obesity ( $\mathrm{BMI} \geq 30)$. CR score: $1(M=2.76, S D=2.83) ; 2(M=4.62$, $S D=2.59) ; 3(M=5.09, S D=2.40) ; 4(M=5.24, S D=1.92)$

\section{4 | Linear regression}

The relationship between all the variables and weight were tested by multiple regression stepwise backward analysis. The statistical parameters associated with the final step of the multiple regression, which represents the best explanatory variables, were as followed: $R^{2}=.253 ; F=32.3, P<.001$. The final four dependent variables of the model were height, $C R$, conscientiousness and age (Table 2).

\section{4 | DISCUSSION}

\section{1 | People with obesity seem to be restrained eaters}

This study shows a positive relation between weight and $C R$ in a sample of the French population. The higher the weight, the higher the CR (Figure 1). Even if it is not possible to test a causal link in this study with latent variable modelling, our results seem to show that people with obesity more frequently intend to eat less and healthier and eat less sugar and fat than other people in order to control their weight. In fact, people affected by obesity do not succeed in so doing.

TABLE 2 BMI predictors

\begin{tabular}{|lcccc|} 
Predictors & Estimate & \multicolumn{1}{l}{ SE } & \multicolumn{1}{l}{$\boldsymbol{t}$} & $\boldsymbol{P}$ value \\
\hline Intercept & -74.97 & 14.86 & -5.04 & $<.001$ \\
\hline Height & 0.83 & 0.08 & 9.86 & $<.001$ \\
\hline Cognitive restraint & 1.15 & 0.27 & 4.27 & $<.001$ \\
\hline Age & 0.16 & 0.050 & 3.16 & .002 \\
\hline Conscientiousness & -0.87 & 0.38 & -2.32 & .021 \\
\hline
\end{tabular}

Abbreviations: BMI, body mass index; $t$, decision statistic.
Although our study cannot prove that decreasing CR would be effective, increasing CR to treat obesity does not seem to be relevant. New studies with latent variable modelling will be necessary.

\subsection{The CR concept}

To study the most effective treatments for people affected with overweight and obesity, it would be necessary to reach a real scientific consensus on what $C R$ is and on how it could be measured. Is CR effective control or is it intention to control? Is it a twodimensional concept that comprises effective control and the intention to control? Due to this problem of conceptual definition, there is no consensus about the relation between CR and weight in the literature.

People with obesity undoubtedly have the intention to control their food intake. In this case, why and how would an increase of selfcontrol be effective? And would such an increase be possible? According to Lowe (2015), "Human beings have the potential for much better self-control of their food intake and body weight than has so far been demonstrated." ${ }^{23}$ Yet, we may wonder whether selfcontrol can really be a goal in itself and whether it is the unique way to go.

\section{3 | Another way}

Self-regulation is a portion of regulation that includes deliberate and automatic aspects. ${ }^{24}$ Deliberate action is necessary to increase selfcontrol or self-regulation. In other words, to avoid eating, one needs to tell oneself not to eat. Yet, according to the ego depletion theory, ${ }^{25}$ the injunction "not to eat" decreases the possibility of selfcontrol.

Intuitive eating and/or mindful eating could be another way to go. ${ }^{26}$ Intuitive eating is often defined as eating according to internal, physiological cues of hunger and satiety rather than according to external or emotional cues. ${ }^{27}$ However, this definition is probably not precise enough. Intuitive eaters eat without thinking about what or how they should eat. They "just eat" and respect their physiological cues with psychological flexibility. Intuitive eaters can eat more than their hunger when they feel the need to or the want to, and they can eat less in the meal after without thinking further about it. They do it "naturally."

Yet, the switch from executive regulations (rules based) to physiological regulations is not as easy as it seems. It is not enough to ask people with overweight or obesity to eat when they are hungry and to stop eating when they are no longer hungry. Indeed, such requests are in fact rules that sound like injunctions and could be CR if followed for the purpose of losing weight.

\section{5 | LIMITATIONS}

Our study has the following limitations: the recruitment of the subjects did not allow us to obtain a representative sample of the 
population, in addition to the size of the sample and the way in which we measured CR, making use of only one item.

\section{6 | CONCLUSION}

The aim of this research was to examine the relation between weight and CR in a sample of the French population. French people with obesity seem to be more restrained eaters than French people without obesity. Yet, it would be necessary to have a scientific consensus on what $\mathrm{CR}$ is and on how to measure it. Indeed, enhancing CR to treat overweight or obesity may not be relevant as people with obesity already have the intention to control their food intake in order to lose or maintain their weight. If intuitive eating may indeed be a way to go, it is not as easy as it seems. As paying attention to physiological cues is a learning process, people with obesity need help to change the way in which they behave with their body.

\section{CONFLICTS OF INTEREST}

No conflict of interest was declared.

\section{REFERENCES}

1. Lowe MR, Thomas JG. Measures of restrained eating: conceptual evolution and psychometric update. Handbook of Assessment Methods for Obesity and Eating Behaviors. New York, NY: Sage; 2009:137-185

2. Stice E, Presnell K, Spangler D. Risk factors for binge eating onset in adolescent girls: a 2-year prospective investigation. Health Psychol. 2002;21(2):131-138. https://doi.org/10.1037/0278-6133.21.2.131.

3. Julien Sweerts S, Apfeldorfer G, Romo L, Kuréta-Vanoli K. Treat or enhance cognitive restraint in individuals suffering from overweight or obesity? Systematic revue of the literature methods definition of cognitive restraint. SOJ Psychol. 2016;3(1):1-8.

4. de Lauzon-Guillain B, Clifton EA, Day FR, et al. Mediation and modification of genetic susceptibility to obesity by eating behaviors. Am J Clin Nutr. 2017;106(4):996-1004. https://doi.org/10.3945/ajen. 117.157396.

5. Singh A, Bains K, Kaur H. Relationship of eating behaviors with age, anthropometric measurements, and body composition parameters among professional Indian women. Ecol Food Nutr. 2017;56(5):411423. https://doi.org/10.1080/03670244.2017.1366317.

6. Banna JC, Panizza CE, Boushey CJ, Delp EJ, Lim E. Association between cognitive restraint, uncontrolled eating, emotional Eating and $\mathrm{BMI}$ and the amount of food wasted in early adolescent girls. Nutrients. 2018;10(9):1279. https://doi.org/10. 3390/nu10091279.

7. Cools J, Schotte DE, McNally RJ. Emotional arousal and overeating in restrained eaters. J Abnorm Psychol. 1992;101(2):348-351. https:// doi.org/10.1037/0021-843X.101.2.348.

8. Polivy J, Herman CP, Younger JC, Erskine B. Effects of a model on eating behavior: the induction of a restrained eating style. J Pers. 1979;47(1):100-117. https://doi.org/10.1111/j.1467-6494. 1979.tb00617x.
9. Wilksch S, Wade TD. Differences between women with anorexia nervosa and restrained eaters on shape and weight concerns, selfesteem, and depression. Int J Eat Disord. 2004;35(4):571-578. https:// doi.org/10.1002/eat.10273.

10. Lowe MR, Doshi SD, Katterman SN, Feig EH. Dieting and restrained eating as prospective predictors of weight gain. Front Psychol. 2013;4(September):577-577. https://doi.org/10.3389/fpsyg. 2013.00577.

11. Karlsson J, Persson LO, Sjöström L, Sullivan M. Psychometric properties and factor structure of the Three-Factor Eating Questionnaire (TFEQ) in obese men and women. Results from the Swedish obese subjects (SOS) study. Int J Obes Relat Metab Disord J Int Assoc Study Obes. 2000; 24(12):1715-1725. https://doi.org/10.1038/sj.ijo.0801442.

12. Ridgway PS, Jeffrey DB. A comparison of the three-factor eating questionnaire and the restraint scale and consideration of Lowe's three-factor model. Addict Behav. 1998;23(1):115-118. https://doi. org/10.1016/S0306-4603(97)00031-2.

13. Stice E, Cooper JA, Schoeller DA, Tappe K, Lowe MR. Are dietary restraint scales valid measures of moderate- to long-term dietary restriction? Objective biological and behavioral data suggest not. Psychol Assess. 2007;19(4):449-458. https://doi.org/10.1037/10403590.19.4.449.

14. Heaven PC, Mulligan K, Merrilees R, Woods T, Fairooz Y. Neuroticism and conscientiousness as predictors of emotional, external, and restrained eating behaviors. Int J Eat Disord. 2001;30(2): 161-166.

15. Vollrath ME, Torgersen S, Torgersen L. Associations of children's big five personality with eating behaviors. BMC Res Notes. 2018;11(1): 654. https://doi.org/10.1186/s13104-018-3768-9.

16. Adams AK, Tomayko EJ, Cronin KA, et al. Predictors of overweight and obesity in American Indian families with young children. J Nutr Educ Behav. 2018;51:190-198. https://doi.org/10.1016/j.jneb.2018. 07.011.

17. Bakalar JL, Barmine M, Druskin L, et al. Childhood adverse life events, disordered eating, and body mass index in US military service members. Int J Eat Disord. 2018;51(5):465-469. https://doi.org/10.1002/ eat.22851.

18. World Medical Association (WMA). World medical association declaration of Helsinki: ethical principles for medical research involving human subjects. JAMA. 2013;310(20):2191-2194. https://doi.org/10. 1001/jama.2013.281053.

19. Rammstedt $B$, John OP. Measuring personality in one minute or less: a 10-item short version of the Big Five Inventory in English and German. J Res Personal. 2007;41(1):203-212. https://doi.org/10.1016/j. jrp.2006.02.001.

20. Godin G, R j S. A simple method to assess exercise behavior in the community. Can J Appl Sport Sci. 1985;10(3):141-146.

21. Palmisano GL, Innamorati M, Vanderlinden J. Life adverse experiences in relation with obesity and binge eating disorder: a systematic review. J Behav Addict. 2016;5(1):11-31. https://doi.org/10.1556/ 2006.5.2016.018.

22. Weathers FW, Litz BT, Herman DS, Huska JA, \& Keane TM. (1993). The PTSD Checklist (PCL): Reliability, validity, and diagnostic utility. In annual convention of the international society for traumatic stress studies. (Vol 462). San Antonio, TX.

23. Lowe MR. Dieting: proxy or cause of future weight gain? Obes Rev off J Int Assoc Study Obes. 2015;16(Suppl 1):19-24. https://doi.org/10. 1111/obr.12252.

24. Nigg JT. Annual research review: on the relations among self-regulation, self-control, executive functioning, effortful control, cognitive control, impulsivity, risk-taking, and inhibition for developmental psychopathology. J Child Psychol Psychiatry. 2017;58(4):361-383. https://doi.org/10.1111/jcpp.12675.

25. Garrison KE, Finley AJ, Schmeichel BJ. Ego depletion reduces attention control: evidence from two high-powered preregistered 
experiments. Pers Soc Psychol Bull. 2018;45:728-739. https://doi.org/ 10.1177/0146167218796473.

26. Kerin JL, Webb HJ, Zimmer-Gembeck MJ. Intuitive, mindful, emotional, external and regulatory eating behaviours and beliefs: an investigation of the core components. Appetite. 2019;132:139-146. https://doi.org/10.1016/j.appet.2018.10.011.

27. Tribole E, Resh E. Intuitive Eating. New York: St. Martin's, Griffin; 2012. 